Acknowledgements

Annette Ittig

Map

A note on transliteration

(iii)

Introduction

Annette Ittig

\title{
Pre-Islamic Textiles
}

Archaeological Evidence for Textiles in Pre-Islamic Iran

Trudy Kawami

\section{Medieval and Safavid Carpets and Textiles}

Masterpieces of Persian Textiles from the Montreal Museum of Fine Arts Collection

Hyatt Salam-Liebich

Zilu

31

Iraj Afshar

Notes on a Zilu Fragment dated 963/1556 in the

Islamic Museum, Cairo

Annette Ittig

Microanalysis of Persian Textiles

Ian Hardin and Frances Duffield

Edmund Herzig

\section{Post-Safavid Carpets and Textiles}

A 'Safavid Cadabi' in the Royal Ontario Museum Reconsidered Marta Dal Farra 
A Group of Qalamkar Fabrics in the Israel Museum

Alisa Baginski

Ziegler's Sultanabad Carpet Enterprise

Annette Ittig

Three Little Known Types of Tribal Storage Bag

Parviz Tanavoli

Glossary of Technical and Structural Terminology

Annette Ittig

\section{Reviews}

Robert Pinner and Walter B. Dennys, eds.,

Oriental Carpet and Textile Studies, vol. III/2

Eleanor Sims

Mechtilde Fleury-Lemburg, Textile Conservation and Research

Sheila Landi

William Eagleton, An Introduction to Kurdish Rugs and Other Weavings and Wilfred Stanzer, Kordi: Lives, Rugs, Flatweaves of

the Kurds in Khorasan

Macguire Gibson

Siawosh Azadi, Carpets in the Baluch Tradition

Brian Spooner

Pamela B. Nelson, ed., Armenian Rugs: Fabric of a Culture

Roger Gardiner

Jennifer Scarce, Women's Costume of the Near and Middle East Yedida Stillman 